\title{
A Coin Acceptor - Mobile Battery Charging using Solar Panel
}

\author{
Ammu Anna Mathew, Anoop J R, S. Vivekanandan
}

\begin{abstract}
A mobile phone charging system based on a coin acceptor system connected with solar panel and battery system is a great service to the public at open places. The coin acceptor thus also provides a great profit to the provider and we can install this in any places easily where people gather more such as railway stations, bus terminals, malls, etc. as this system is portable. The energy is obtained from solar panel, so the running cost is also very low. The system is designed with ARDUINO ATMEGA 32 microcontrollers, thus the input pulses while coin acceptor is active is sent to the battery module and mobile phone can be charged. The system will work even in cloudy days because a battery is also included in it.
\end{abstract}

Keywords: ATMEGA 32 microcontroller, battery, coin acceptor, $P V$ panel, solar panel

\section{INTRODUCTION}

$\mathrm{V}$ arious technologies are now developing in the field of electronics. One of the main technologies in our world is mobile phones. Nowadays it has become common among our people and the world can't think about a globe without mobile phones. People are using different types of mobile phones from different companies with various specifications as needed by the customer. One of the common factors between all the mobile phones is the power needed for the life of mobile phones [1]. Some manufacturers are entering the mobile market with portable chargers, but not all are functioning in the same way as their competitors.

The emerging technologies in electronics give smart phones with sophisticated technology having better battery power which will work for two or three days. But due to the heavy use by the customers, most of them last only for six to seven hours. So here a technique for charging the mobile phones while we are away from our home or office. In case of energy it is also depleting from day to day, so we are using solar energy for this purpose. Solar mobile chargers are devices that can charge your mobile phone with the sunray [2]. Batterystuff.com has a good overview of the different types of solar chargers available on the market. The solar

Revised Manuscript Received on April 21, 2020.

* Correspondence Author

Ammu Anna Mathew, Research Scholar, School of Electrical Engineering, Vellore Institute of Technology, Vellore, India, E-mail: ammumelekuttu@gmail.com

Anoop J R, M-TECH in Electrical Machines, APJ Abdul Kalam Technological University, E-mail: anoopjohnson92@gmail.com

Dr. S. Vivekanandan*, Associate Professor, School of Electrical Engineering, Vellore Institute of Technology, Vellore, India E-mail: svivekanandan@vit.ac.in

(C) The Authors. Published by Blue Eyes Intelligence Engineering and Sciences Publication (BEIESP). This is an open access article under the CC BY-NC-ND license (http://creativecommons.org/licenses/by-nc-nd/4.0/) charger is a charger that has voltage and current regulation for different applications with different power levels to meet the requirements, and also covers the battery and its controller with a solar system of up to 500 watts. An example of a solar charging circuit used to charge a lead-acid Ni-CD battery with solar energy is mentioned. This circuit charges a 6 Volt $45 \%$ battery with different voltages. The main components used in that project are solar panel, battery charger and the DC / DC converter. The solar-powered battery chargers have a photovoltaic panel (PV) to convert solar energy into electricity and a DC converter to control the voltage and current regulation of the batteries and their controller. The output voltage can become unstable as the light radiation that falls on the solar module can vary. The electricity from the solar module is fed to a charge controller, which is then fed to the output battery to store the energy. The output of the battery is connected to an inverter, which provides the user with an outlet to access the stored energy. The world's first model is the Strawberry Tree public solar charger, invented by the Strawberry Energy Company. Solar panel, battery and inverter can be purchased as shell parts, while the MPPT charge controller is designed and built by a Solar Knight [3]. In this project, the concept of a coin-based mobile battery charger working with the main power of the solar energy and its potential for the use in a variety of applications are discussed. Solar-powered charging stations are designed to charge devices outdoors in an environmentally friendly way. These systems convert solar energy into electricity and are available in several of forms such as solar panels, solar cells etc. This article describes a mobile charger that uses a coin-based solar tracking system with a solar panel and a battery pack. This paper describes a mobile charger with an electric battery and the use of coin-based solar tracking systems. The mobile phone business is currently in the midst of a major shift away from the traditional use of batteries for mobile phones towards a more efficient and cost-effective solution. The technique is charging mobile phones in the public places by inserting a coin and the energy is taken from sun. By using the solar panels, light energy is converted and it can be used for the supply and vending machine for collecting coins. As we are installing it in public places it will give a profit to the government. The people now are addicted to mobile phones so a coin based mobile charging portable system is an efficient and profit enabling technique. The coin based system will be working based on the programmed ARDUINO ATMEGA 328 and this system can be introduced in kiosks. This is a coin-based mobile phone charger that takes the form of a mobile phone that can be recharged in public places by inserting coins. The mobile charging circuit is the device that can charge the cell phone battery in a short time for only a few cents per charge.

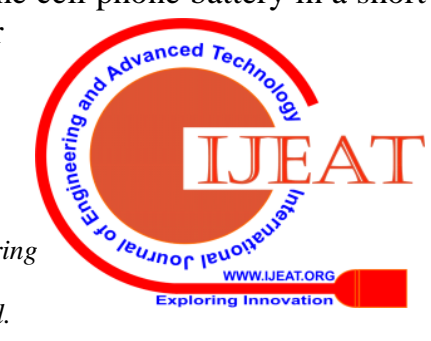


This system can charge a mobile phone for a certain amount of time by inserting the right coins in the right place and at the right time, without the need for battery charger. Mobile phones have great

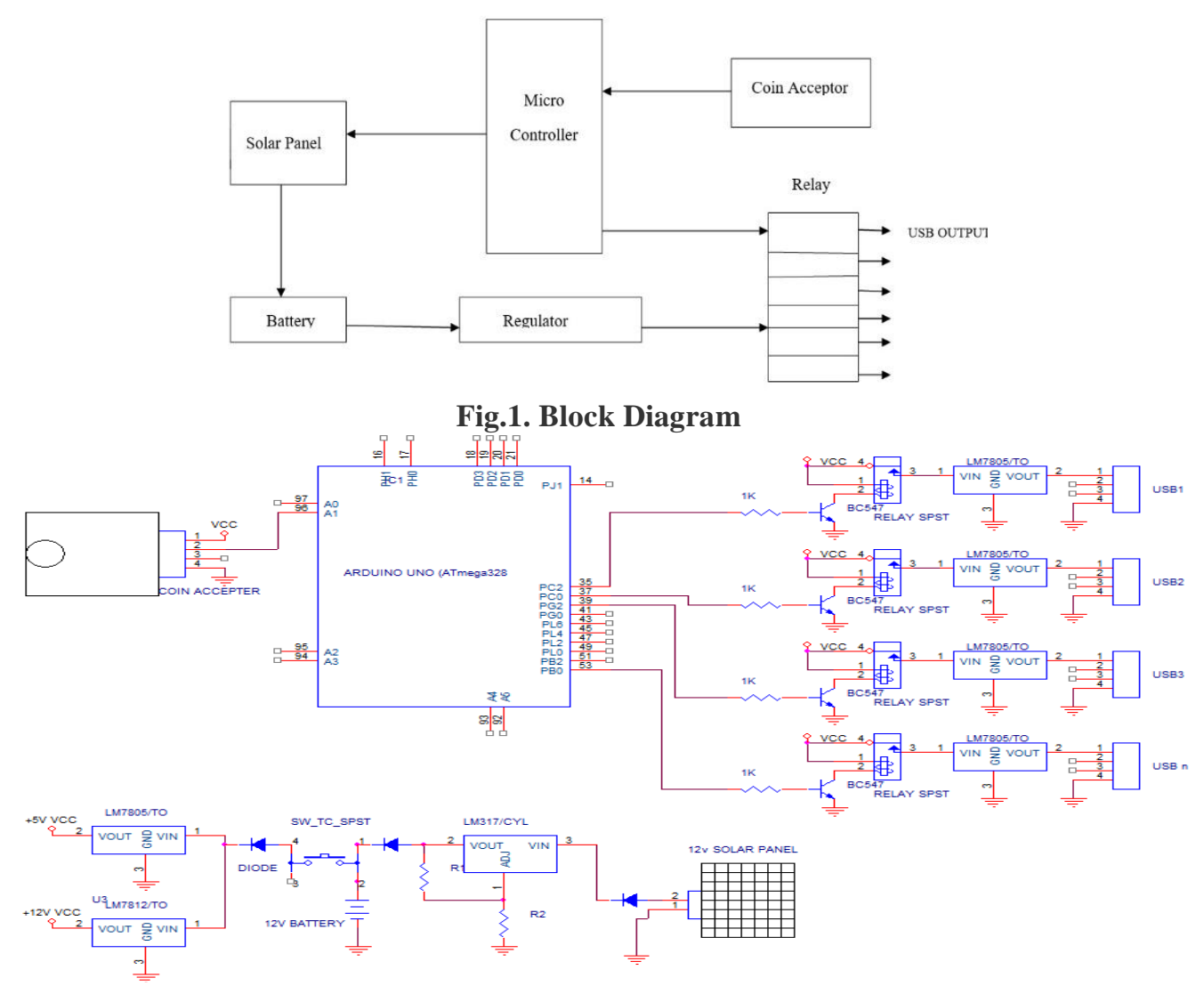

Fig.2. Circuit Diagram

value in today's market and have become an important source of business and personal communication [4].

The mobile phone business is currently worth billions of dollars and supports millions and it has become one of the most important business areas in the world [5]. The system includes a coin-based mobile solar charger which charges the mobile phone via a solar panel on the roof of a house or via small solar panels on the roof. The battery of phone gets drained at favorable times when access to a standard charger is not possible. A universal mobile battery-based charger with a coin was designed and developed on a paper by researchers at the University of California, Berkeley's Department of Electrical Engineering and Computer Science. To solve this problem, they developed a novel solar charger for mobile phones with a battery capacity of 1 kilowatt-hour. The device was a vending machine were the user plugs the phone into one of the adapters, inserts the coin and plugs it into the solar panel with a 1 kilowatt-hour battery capacity of $1 \mathrm{kWh}$. The problem statement was to create a charger that does not need an electrical outlet under any circumstances as we know the difficulties of finding outlets to charge their phones, but also the difficulties of recharging a mobile battery at the kiosk. The coin-based mobile phone charger is very useful for the public as this is a place to recharge mobile phones at any time. If you use your mobile phone at home or in the office under charging conditions, it can be very helpful for you. It is also very beneficial for a person if the coin is used to charge the constant current for a certain period of time, because it is used to charge a mobile battery at the kiosk [6].

\section{BLOCK DIAGRAM}

The block diagram consists of a solar panel, micro controller, regulator, battery, coin acceptor and a relay. The energy from solar panel is converted and stored in the battery. The stored energy from the battery is converted by using a regulator. The whole working is controlled by a micro controller ARDUINO ATMEGA. The main part is the coin acceptor where it collects the coins and will give start signal to the micro controller.

\section{CIRCUIT DIAGRAM}

The circuit works as follows: the coin is placed on the vending part of the coin based mobile charging system as shown in fig. 2. The main components of the system are a solar panel, 12V battery, ARDUINO ATMEGA 328, coin acceptor, resistors, diodes, transistors, relays and USB ports. The $12 \mathrm{~V}$ battery is charged with the help of a solar panel. The transistors, diodes and voltage regulator regulate the voltage from the $12 \mathrm{~V}$ battery.

This system can be placed at public places, thus everyone can access the mobile charging facility [7]. The system consists of a coin recognition module that recognizes the valid coins and then generates a signal to the ARDUINO ATMEGA 328 for further action.

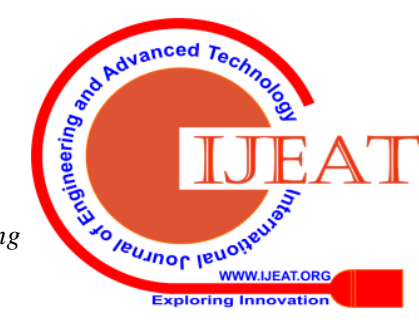




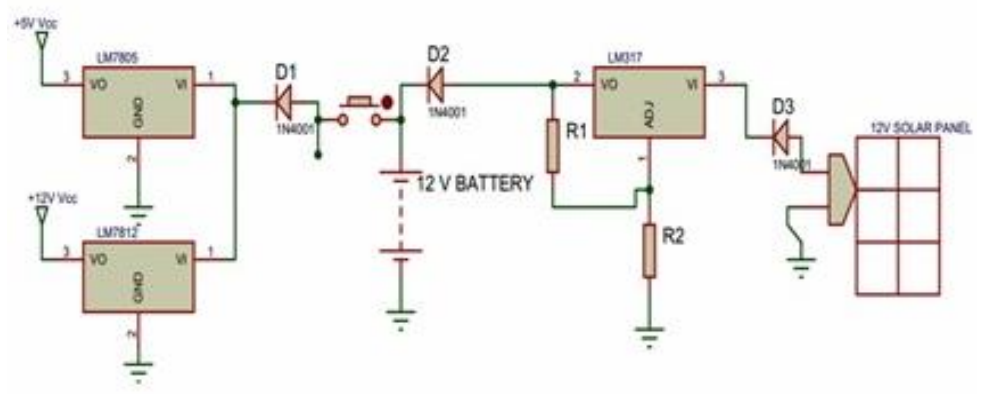

Fig.3. Circuit Diagram for the Solar Panel Module

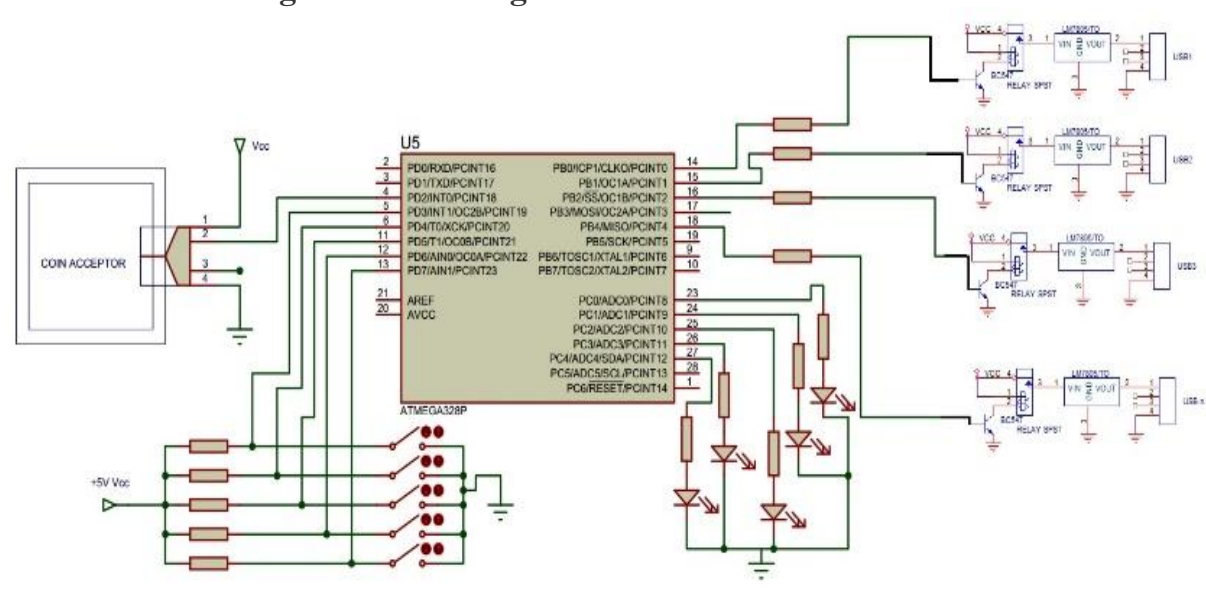

Fig.4 Circuit Diagram of Coin Acceptor with Switches

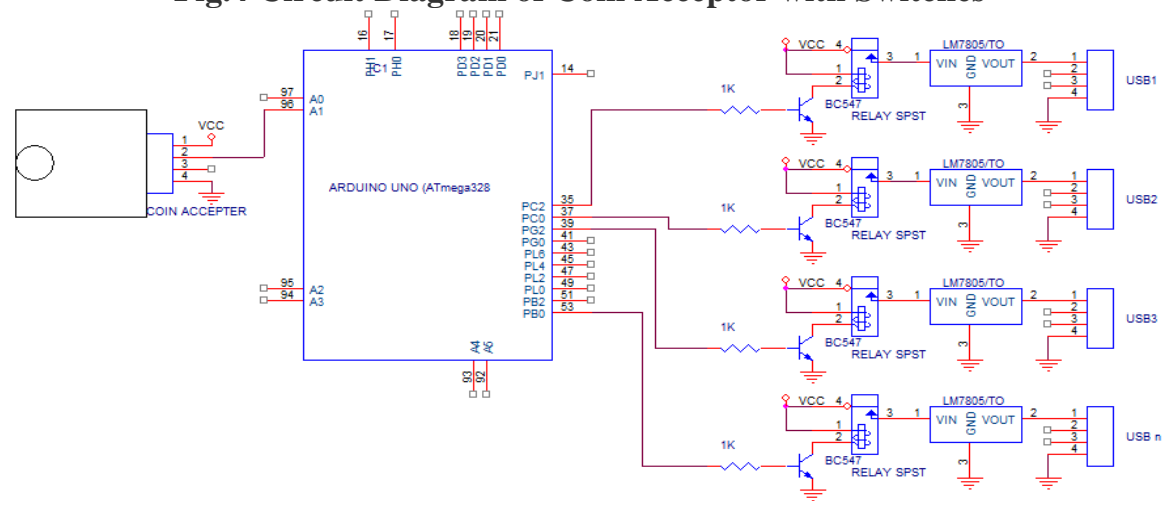

Fig. 5 Circuit Diagram of Coin Acceptor without Switches

When the valid coin is recognized, it will provide a $5 \mathrm{~V}$ supply to the mobile phones. Once the charging starts, the ARDUINO starts a reverse countdown timer to display the charging time for that mobile phone. If the customer needs more power, another valid coin has to be inserted to the system thereby making the ARDUINO controller to add extra time to the system for charging. This system can be placed in public places for the use of everyone and it can be a profitable earning for the provider [8].

Circuit diagram for the solar panel voltage regulator and battery unit is shown in figure 3 . The sun rays falling on the panel are converted to energy and it is passed through a LM317 regulator IC and also is stored in a battery. The specialty of this circuit is that if the solar energy is sufficient then it can be directly used by passing through the regulator. If solar energy is not sufficient for charging we can take the energy from the battery. For this switching process, a change over switch is also provided.

The main circuit diagram for the coin based system is designed in two ways. In first circuit, a direct is given to the USB ports from battery and microcontroller. In the second circuit, the energy for the USB ports is given by separate switches. The circuit for the coin acceptor with separate switches is shown in the fig. 4 . The circuit diagram for the coin based solar mobile phone charging without switches are shown in figure 5 .

\section{COMPONENTS}

\section{A. Coin Acceptor}

The coin acceptor mainly works on the basis of the diameter of the coin which will be placed as shown in fig.6. The standard diameter of coin is between $10.8 \mathrm{~mm}$ to 25.1 $\mathrm{mm}$ in diameter and this can be done by programming. This works when a registered
Published By:

Blue Eyes Intelligence Engineering \& Sciences Publication

(c) Copyright: All rights reserved.

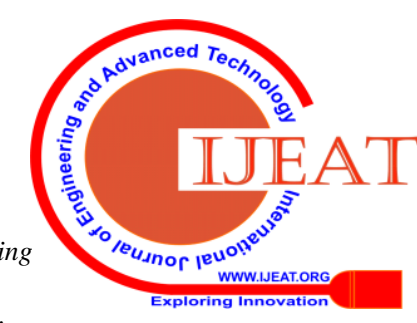




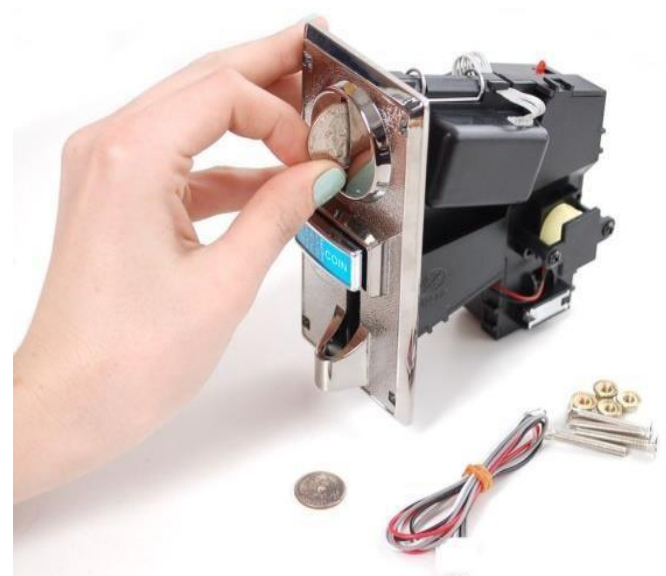

Fig. 6 Coin Acceptor

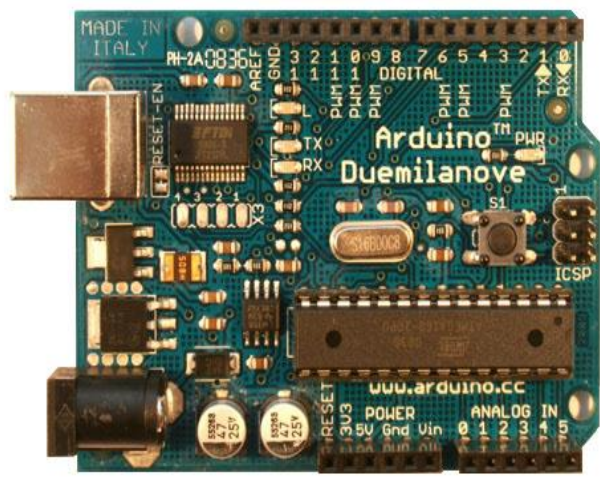

Fig 7. ARDUINO Duemilanove

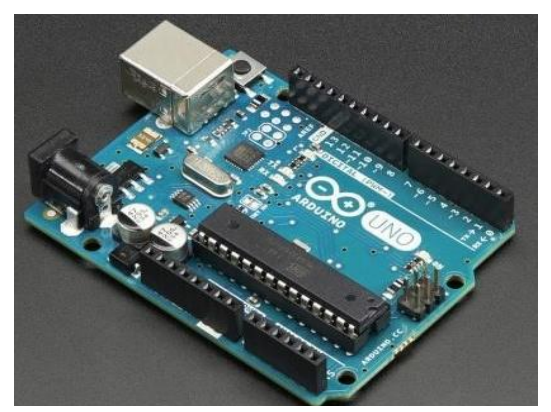

Fig.8. ARDUINO UNO R3

coin is placed in the system. Once the coin is inserted a signal in the form of pulse wave for 15 to 70 milliseconds will be produced and it can be changed [9].

The system also monitors the size of the coin, solidity and the speed the coin which is placed. The current peak is 25milli ampere and the peak current for the solenoid is 350 $\mathrm{mA}$ and hence it can be programmed for one coin. This will never works for the coins with hole.

\section{B. Arduino Uno R3 (Atmega 328)}

The former version of ARDUINO Uno R3 is Duemilanove as shown in fig. 7. The variation of the Uno R3 is that it has sophisticated USB connector and an interface. The ARDUINO Uno R3 in fig. 8 can be used for sensing purposes in the circuits because we can receive a different input from various sensors and it can be well controlled in this system. The programming is also very simple in the case of ARDUINO. The ARDUINO board has a weight of $26 \mathrm{gm}$ and dimensions are as follows: length 2.98inch, width 2.23inch and thickness $0.5 i n c h$.
The operating voltage for the board is $5 \mathrm{~V}$ DC but we can give an input voltage of 6 to 12 Volts and can be a maximum up to $20 \mathrm{~V}$. The UNO board contains a total of 14 digital ports and 6 analog ports with a clock speed $16 \mathrm{MHz}$

\section{Voltage Regulators}

Every electronic circuit requires a regulated power supply for its proper working and safety. The purpose is that all the electronic devices comprises of semiconductor devices therefore it requires a regulated supply and the variations in the supply can be controlled by using the voltage regulators. Here in this circuit we are using LM7805, LM7812, and LM317.

\section{RESULT AND DISCUSSION}

A novel technique for outside mobile charging with the coin acceptor module is explained. The block diagram for the entire system and the microcontroller Arduino ATMEGA working are discussed. The circuit diagram for the system with two modes of operation, one circuit without switches can be installed at any locality with unlimited charging and common ports, while the latter circuit with switches provides separate control for each port. If a timer switch is used, then the system can be made more automatic. The main highlight is this module works with direct sunlight energy by using a solar panel. Circuit for solar panel energy conversion with voltage regulators gives a regulated supply for the module. If it is cloudy we get the power from the battery, so the system is cost-efficient and energy-efficient.

\section{CONCLUSION}

A novel method for mobile phone charging based on a coin acceptor is designed and will be of great use to the public. The circuit is mainly controlled by an ARDUINO microcontroller and the system is designed for the charging of five mobile phones at a time. The circuit diagram for the designed prototype and the main components are also discussed above. The circuit diagram for two different modes is also included.

\section{REFERENCES}

1. Pastre, M. Krummenacher, F. Robortella, R. Simon-Vermot, R. Kayal, M. Ecole Polytech. Fed. de Lausanne, Lausanne, "A fully integrated solar battery charger Circuits and Systems", TAISA Conference, 2009.

2. Barth, H. Schaeper, C. Schmidla, T. Nordmann, H. Kiel, M. van der Broeck, H. Yurdagel,Y. Wieczorek, C. Hecht, F. Sauer, D.U., "Development of a universal adaptive battery charger as an educational project”, Power Electronics Specialists Conference, Pg 1839 - 1845, 2008.

3. Bedford, B. D.; Hoft, R. G. et al. (1964). Principles of Inverter Circuits New York: John Wiley \& Sons, 1964

4. Pulvirenti, F Milazzo, P. Ursino, R, "Charger power switch for mobile phones, Analog and Mixed IC Design”, Proceedings. 1997 2nd IEEE-CAS Region 8 Workshop , Pg 97 - 100, Sep 1997.

5. Weidong Xiao, William G. Dunford, Patrick r. Palmer and Antoine Capel, "Regulation of Photovoltaic voltage," IEEE Trans. Industrial Electronics, vol. 54 no.3, pp. 1365-1373, June 2007.

6. K S.B.Sridevi, A. Sai Suneel. Nalini, "International Journal of Innovative Research in Science, Engineering and Technology", ISSN: 2319-8753, ISO 3297: 2007 Vol. 3, Issue 2, pp.9603-9608, February 2014.

7. M.S.Varadarajan,"Coin Based Universal Mobile Battery Charger",IOSR Journal of Engineering (IOSRJEN), Volume 2, pp 1433-1438, 2012. 
8. Henry Shu-Hung Chung, K. K. Tse , S. Y. Ron Hui , C. M. Mok , M. T. Ho ,"A Novel Maximum Power Point Tracking Technique for Solar Panels Using a SEPIC or Cuk Converter," Proc. IEEE Transactions On Power Electronics, pp. 717-724, 2003.

9. Daniel A. Pritchard, "Sun Tracking by Peak Power Positioning for Photovoltaic Concentrator Arrays", Control systems magazine, 2011.

10. T.Gunawan, Mirakartivi, Rashidahabubahakar, "Development of portable charger for mobile phone using arduino micro controller during disaster recovery," Proc. IEEE Advanced Computer Science Applications and Technologies (ACSAT), pp 218 - 222, 2013.

11. Suchika Malik, Parveen Bajaj, Mukhwinder Kaur, "Sample Coin Recoginition System using Artificial Neural Network on Static Image Database," International Journal of Advanced Research in Computer Science \& Software Emerging, pp.762-770, 2014

12. S. Banu Prathap, R. Priyanka ,G. Guna, Dr. Sujatha,"Coin based cell phone charger," International Journal of Enginnering Research \&Technology, pp 1-4, 2013.

\section{AUTHORS PROFILE}

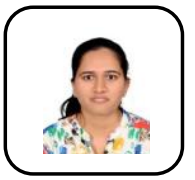

Ammu Anna Mathew received her B.tech degree in Electrical and Electronics Engineering from Kerala University, India, in 2010 and M.E. degree in Applied Electronics from Sathyabama University, Chennai, India, in 2013. She worked as an Assistant Professor in Department of Electrical and Electronics Engineering at Lourdes Matha College of Science and Technology, Trivandrum, India. She is currently pursuing the Ph.D degree with School of Electrical Engineering from VIT University, Vellore, India. She is a life member of ISTE. Her current research interests include flexible wearable biosensor fabrication.

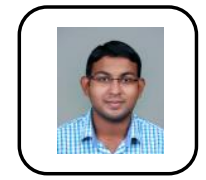

Anoop J R, received B.tech degree in Electrical and Electronics Engineering from Kerala University, India, in 2015 and M-TECH in Electrical Machines from APJ Abdul Kalam Kerala Technological University in 2017. He has various publications in International and National Journals related to solar power and booster circuits. He is also a member of the International Engineers Association.

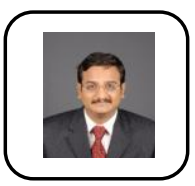

Dr. S. Vivekanandan received his B.E. degree in Electronics and Instrumentation from Anna University, India and M.E. degree in Process Control Instrumentation from Annamalai University, India, in 2002 and 2004, respectively, and the Ph.D. degree from Vellore Institute of Technology, Vellore India, in 2015. He is currently working as Associate Professor in School of Electrical Engineering, VIT University,Vellore. He has authored more than 30 research articles which is published in different reputed International Journals. He is also a faculty coordinator of ISA Student Section District 14. He received best mentor award from ISA in 2017 from USA. He has also filed a patent on IoT based biosensor for chronic disease diagnosis. He is also a life member in IEEE, ISA and IETE. His current research interest includes biomedical devices and development of cascade control systems for biomedical applications.

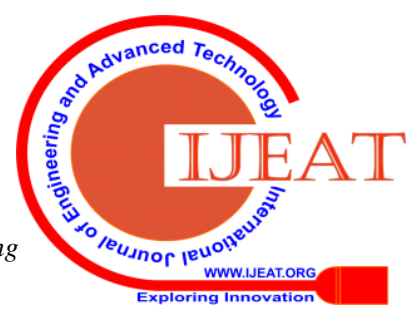

